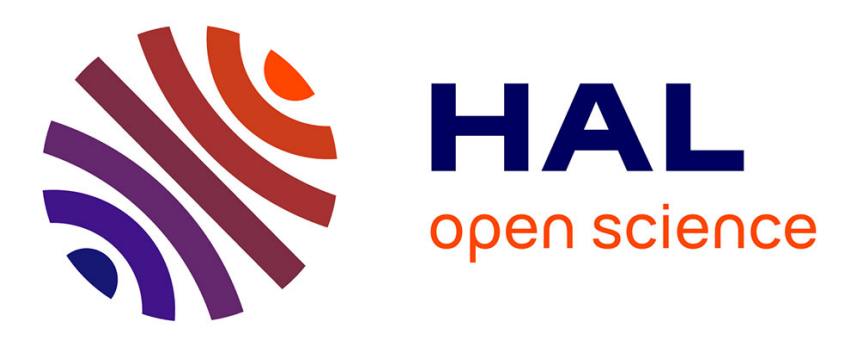

\title{
"Solvent-free" ultrasound-assisted extraction of lipids from fresh microalgae cells: A green, clean and scalable process.
}

Fanny Adam, Maryline Abert-Vian, G. Peltier, Farid Chemat

\section{- To cite this version:}

Fanny Adam, Maryline Abert-Vian, G. Peltier, Farid Chemat. "Solvent-free" ultrasound-assisted extraction of lipids from fresh microalgae cells: A green, clean and scalable process.. Bioresource Technology, 2012, 114, pp.457-465. 10.1016/j.biortech.2012.02.096 . hal-01329566

\section{HAL Id: hal-01329566 https://hal.science/hal-01329566}

Submitted on 29 May 2020

HAL is a multi-disciplinary open access archive for the deposit and dissemination of scientific research documents, whether they are published or not. The documents may come from teaching and research institutions in France or abroad, or from public or private research centers.
L'archive ouverte pluridisciplinaire HAL, est destinée au dépôt et à la diffusion de documents scientifiques de niveau recherche, publiés ou non, émanant des établissements d'enseignement et de recherche français ou étrangers, des laboratoires publics ou privés. 


\title{
"Solvent-free" ultrasound-assisted extraction of lipids from fresh microalgae cells: A green, clean and scalable process
}

\author{
Fanny Adam ${ }^{\mathrm{a}}$, Maryline Abert-Vian ${ }^{\mathrm{a}, *}$, Gilles Peltier $^{\mathrm{b}}$, Farid Chemat ${ }^{\mathrm{a}}$ \\ a Université d'Avignon et des Pays de Vaucluse, INRA, UMR408, F-84000 Avignon, France

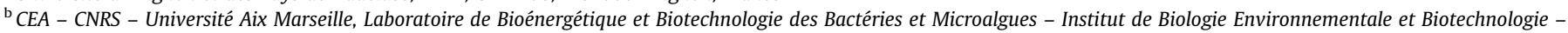 \\ UMR 6191 CEA Cadarache - 13108 Saint-Paul-lez-Durance, France
}

\section{A R T I C L E I N F O}

\section{Article history:}

Received 15 December 2011

Received in revised form 17 February 2012

Accepted 18 February 2012

Available online $\mathrm{xxxx}$

\section{Keywords:}

Ultrasound-assisted extraction (UAE)

Bio-oil

Response surface methodology (RSM)

Nannochloropsis sp.

Scanning electron microscopy (SEM)-gas

chromatography (GC)

\begin{abstract}
A B S T R A C T
In order to comply with criteria of green chemistry concepts and sustainability, a new procedure has been performed for solvent-free ultrasound-assisted extraction (UAE) to extract lipids from fresh Nannochloropsis oculata biomass. Through response surface methodology (RSM) parameters affecting the oil recovery were optimized. Optimum conditions for oil extraction were estimated as follows: (i) $1000 \mathrm{~W}$ ultrasonic power, (ii) 30 min extraction time and (iii) biomass dry weight content at $5 \%$. Yields were calculated by the total fatty acids methyl esters amounts analyzed by GC-FID-MS. The maximum oil recovery was around $0.21 \%$. This value was compared with the one obtained with the conventional extraction method (Bligh and Dyer). Furthermore, effect of temperature on the yield was also investigated. The overall results show an innovative and effective extraction method adapted for microalgae oil recovery, without using solvent and with an enable scaling up.
\end{abstract}

(c) 2012 Elsevier Ltd. All rights reserved.

\section{Introduction}

In recent past years, stimulated by that international energy crisis, research projects on alternative and renewable energies including the concept of producing biofuels from the intensive culture of microalgae, as a third-generation biofuel, have been proposed. This research is specially aimed at facilitating the transition to a lowcarbon economy with an emphasis to more diversified energy resources and encouraging investments in sustainable sources. The concept to harness energy released by microalgae seems to be increasingly less marginalized for microalgae have been estimated as very good candidates for fuel production (algaefuel). Their main advantages are their higher photosynthetic efficiency, higher biomass production and faster growth, compared to other energy crops (Mata et al., 2010). Microalgae can be produced in large scale on non-arable lands and do not need potable water to grow. Consequently, there is no competition with food production for a growing human population (Singh and $\mathrm{Gu}, 2010$ ).

A few microalgae strains are known to contain high level of lipids, and they represent a great interest in the research of sustainable sources for biodiesel production. The lipid and fatty acid amounts of microalgae differ according to the culture conditions.

* Corresponding author. Address: Universite d'Avignon et des Pays de Vaucluse, INRA, UMR408, 33 rue Louis pasteur, 84000 Avignon, France. Tel.: +3349014 44 32; fax: +33490144441.

E-mail address: maryline.vian@univ-avignon.fr (M. Abert-Vian).
For instance, in conditions of nitrogen starvation, some species can accumulate high amounts of triacylglycerides (TAGs), the major feedstock for biodiesel production (Scott et al., 2010).

Lipids extraction process from dry or wet microalgae biomass and its efficiency represent an important key step in the process of biodiesel production. So it is essential to find an extraction one with an efficient device to increase the lipid extraction yield (Lee et al., 2010; Mercer and Armenta, 2011). Various methods have already been used for this purpose (Ranjan et al., 2010), most of them being assisted with solvent, such as Soxhlet extraction with $n$-hexane (Halim et al., 2011), Bligh and Dyer method with a chloroform/methanol solvent mixture (Bligh and Dyer, 1959), supercritical fluid extraction with $\mathrm{CO}_{2}$ (Andrich et al., 2005) or methanol (Patil et al., 2010). However, for other authors, processes do not necessary require this solvent assistance, they use bead mills (Richmond, 2004), expeller press procedure, extraction with enzyme (Sander and Murthy, 2009), microwave assisted pyrolysis extraction (Du et al., 2011), ultrasound and microwave assisted extractions, pulsed electric field and hydrothermal liquefaction (Brown et al., 2010). Compared to traditional chemical methods involving solvent addition (usually toxic chemicals such as benzene, ether and hexane), solvent-free extraction is often a more ecologic (in terms of sustainable development) and a more economic process, indeed, it need no supplementary energy to separate phases and to eliminate the solvent if no final product recirculation system exists. At last it avoids the risk of medium contamination. 
In some studies dedicated to microalgae oil recovery, a combination between mechanical and chemical extractions was found, such as an ultrasonic-assisted extraction with ethanol (Wiyarno et al., in press), an ultrasound-mediated Bligh and Dyer method (Ranjan et al., 2010), an ultrasound-mediated extraction in $n$-hexane (Ranjan et al., 2010; Cravotto et al., 2008), an ultrasonic water bath device with chloroform/methanol (Krienitz and Wirth, 2006), a microwave extraction with hexane (Balasubramanian et al., 2011; Cravotto et al., 2008), a pulsed electric field prior to a solid/liquid extraction using ethanol (Gottel et al., 2011).

While these processes differ in their environmental (solvent volume and toxicity) and economic (extraction time, presence of solvent) impacts, an important issue to consider is the scale of the process. In most cases, extraction realized is at the laboratory scale, and therefore the challenge is to upscale the process without losing performance and quality in oil recovery, cost-efficiency and environmental impact.

The current work aims at optimize the oil extraction from microalgae cells by using an innovative ultrasound technology. In the light of earlier publications, it has been decided to develop an eco-extraction process (in a context of sustainable development: solvent-free extraction is a preferred option) on fresh microalgae biomass at the pre-industrial scale with a powerful and adaptable ultrasonic device for lab testing and industrial processing of liquids.

Applications of ultrasounds have been widely developed in the industry and are still an active research field, probably because it is a key technology in achieving the objective of sustainable "green" chemistry. Ultrasounds were preliminarily used as a control system in the food industry by using their high frequency (also called diagnostic ultrasounds), but more and more interest has been given to high power (or low frequency) ultrasounds as an innovative and alternative process. The effect of ultrasounds on extraction yields is attributed to the microstreaming and heightened mass transfer produced by cavitation and bubbles collapse, resulting in cells destruction.

Extraction is a strategic processing step in recovering oils from microalgae cells before transesterification stage (in a two-stage procedure). As outlined above, various conventional methods are available for oil extraction, but they generally require long extraction times, rely on toxic petroleum-based solvents and require high energy inputs. Ultrasound-assisted extraction is an alternative technique able to solve problems associated with the conventional methods, as the process simplifies handling and work-up conditions, gives higher purity of the final product, eliminates post-treatment of waste-water. It has also been shown to be more economical and eco-friendly: the process can be completed in a few minutes instead of a few hours with high reproducibility. It also reduces the amount of solvent (sometimes no solvent is used) as well as the energy required compared to conventional methods, by working at lower temperatures or by refraining from the expensive elimination of the solvent (Chemat et al., in press).

The aim of this work is to demonstrate the potential of ultrasonic assistance as an eco-process for lipids extraction from a fresh matrix of just harvested microalgae biomass. Influence of operating parameters on the extraction yields will be studied and evaluated. For this purpose, lipid classes' contents and fatty acids methyl esters profiles have been analyzed using HP-TLC and GC-FID-MS as fine analytical methods. Experimental studies in batch mode are applied on the high power ultrasonic device $1000 \mathrm{~W}, 20 \mathrm{kHz}$, which represents a good interface between lab and industrial processing. A response surface methodology obtained from a multivariate study (central composite design) was used to investigate the performance of the extraction procedure, to study the relevance of the variables required in extraction and to determinate the final optimal settings.
Nannochloropsis oculata was chosen as a microalgae model. This strain is prized for its capacities to remove oils (22-29\% dry weight biomass) (Mata et al., 2010) suitable for biodiesel production. Oil extracted from this strain consisted of saturated and unsaturated fatty acids like, such as palmitic acid, oleic acid and linoleic acid, which are common fatty acids used for biodiesel production, but also good candidates to improve the quality of the biodiesel (Gerhard, 2008). Nannochloropsis sp. is also considered as one of the most promising EPA (eicosapentaenoic acid) producers (Hanhua and Kunshan, 2003). This compound is widely used in mariculture as a very good source of omega-3 polyunsaturated fatty acids.

\section{Methods}

\subsection{Strain, culture and harvesting conditions}

N. oculata was supplied by Alpha Biotech Company (Asserac, Loire Atlantique), France. The cultivation system is a mixture of photobioreactor and outdoor raceways of up to $10 \mathrm{~m}^{3}$. The culture media is made of sea water with an addition of a nitrogen source $(+\mathrm{N})$. Harvesting is being performed by centrifugation at around $5000 \mathrm{rpm}$, resulting in a $30 \%$ dry weight paste that is directly frozen $\left(-25^{\circ} \mathrm{C}\right)$.

\subsection{Conventional lipids extraction methods}

Lipids content of $N$. oculata cells was determined using a modified procedure described in (Bligh and Dyer, 1959). Typically, a solution of EDTA ( $1 \mathrm{ml}, 1 \mathrm{mM}$ in $0.15 \mathrm{M}$ acid acetic) was added to $10 \mathrm{mg}$ of fresh microalgae at about $20 \%$ dry weight (DW). The mixture was transferred to a glass tube with a Teflon-lined screw cap and, after addition of $3 \mathrm{ml}$ of a mixture methanol-chloroform $(2: 1$, $\mathrm{v} / \mathrm{v}$ ), was vortexed (VX-2500, VWR). Then, $1 \mathrm{ml}$ of chloroform and $0.8 \mathrm{ml}$ of $\mathrm{KCl}(0.88 \% \mathrm{w} / \mathrm{v})$ were added before vortexing and centrifuging at $4000 \mathrm{rpm}$ for $2 \mathrm{~min}$. The lower chloroform phase was transferred to a new glass tube. Cells were then extracted again with hexane, centrifuged and the supernatant was combined with the previous chloroform extracts. Lipid extracts were dried under a stream of $\mathrm{N}_{2}$ and re-suspended in solvent for HP-TLC or GC-FID analysis.

\subsection{Ultrasonic assisted extraction in batch of aqueous medium}

Ultrasound-assisted extraction was carried out using an ultrasonic device operating at low frequencies $(20 \mathrm{kHz})$ with a $1000 \mathrm{~W}$ ultrasonic processor (UIP1000hd, Hielscher Ultrasonics, $\mathrm{GmbH}$, Germany). The transducer was customized with a B2-1.8 booster as booster horn and a BS2d34 standard titanium sonotrode (frontal area: $9 \mathrm{~cm}^{2}$ ). The computer-supported control of ultrasonic processor was operated by the UPCCTRL V3.2 WIN software. This program allows the pre-adjustment of the control parameters pulse and amplitude of ultrasonic processor. As process parameters, the gross and net power and the energy input into the medium to be treated are acquired. A temperature probe is also added in the liquid. Data collection is made and registered 10 times per second. The global ultrasonic system works as a self-contained unit, including transducer, sonotrode, flow cell and closed loop refrigeration. These modules are located in a double-wall stainless steel cabinet that comes with a very effective sound insulation (Rittal GmbH \& Co., Germany). Ultrasound-assisted extraction was processed in a double glass reactor thermostated by a recirculated chiller module system (Buchi).

$100 \mathrm{~g}$ of fresh $N$. oculata (30\% DW) was extracted at each experiment; an antioxidant, ButylHydroToluene (BHT) was added in the 
medium. Percentage of microalgae dry matter can be varied in a controlled manner by appropriately modifying distilled water content.

\subsection{Post-treatment of samples}

After extraction, oil was separated from aqueous suspension by using a saline solution $(100 \mathrm{ml} \mathrm{NaCl} 0.9 \% \mathrm{~m} / \mathrm{w})$ for demulsifying oil/water emulsion. A centrifugation step was operated (5000 rpm-10 min) by adding necessary few milliliters of an hexane/isopropanol solvent mixture $(3: 2, \mathrm{v} / \mathrm{v})$; indeed, the lipid phase did not clearly appear as the content of lipids was quite low in the global aqueous solution. A day-lasting setting step followed and the upper organic phase was separated. It was finally filtered under vacuum with a Buchner funnel using a glass microfibers paper filter (90 mm, Fisher Bioblock). The filtered solution was then dried with anhydrous sodium sulfate and the residual organic volume was stored at $-20^{\circ} \mathrm{C}$ for further direct lipid classes' analysis (HPTLC).

\subsection{Experimental design and statistical analysis}

In order to obtain the best lipids extraction conditions from $N$. oculata with this ultrasound-assisted innovative method, a mathematical model is applied. Therefore, by using statistical technique, various parameters can be tested with a minimum number of experiments while reducing energy, time and cost of testing. In fact, this also goes towards the use of the ultrasound process. A central composite design-CCD also called Box-Wilson design was used in order to determine the effect of each factor and, the most important point, their interactions. The CCD contains a fractional factorial design with center points which is increased with a group of 'star points' allowing the estimation of curvature. The star points establish new extremes for the low and high settings of all factors. The star points are at a distance $\alpha$ from the center and the accurate value of $\alpha$ and number of center point runs in the design depends on properties desired for the design and the number of factors involved. Table 1 illustrate the factor settings and matrix required for the $\mathrm{CDD}$, including the values corresponding to the levels of factors and treatments, assuming three-factors with low and high settings. It must be noted that the response variable $Y$ represents the total recovered fatty acid methyl esters amounts $(\mu \mathrm{g} / \mathrm{g}$ dry weight) which was obtained by GC-FID-MS analysis. Twenty experiments were realized in this experimental design with $100 \mathrm{~g}$ of fresh microalgae biomass disposed in a double glass reactor kept at room temperature (thermostat at $20^{\circ} \mathrm{C}$ ) and with adjunction of distilled water according to the percentage of dry weight (DW) applied.

Statistical analysis was performed with an ANOVA analysis using Statgraphics 6.0 (Statistical Graphics Corporation, Rockville, MD, USA) to investigate factor effects (ultrasonic power, extraction time and percentage of dry weight) and interactions among them on the total recovered fatty acid methyl esters amounts.

The effect of three independent variables on semi-quantitative headspace analysis of lipid contents released from 20 models was determined using a response surface analysis. The generalized polynomial model proposed for predicting the response variable is given below:

Table 1

Levels and variable involved.

\begin{tabular}{clll}
\hline Levels & $x_{1}$ Power $(\mathrm{W})$ & $x_{2}$ Extraction time $(\mathrm{s})$ & $x_{3} \%$ dry weight $(\mathrm{DW})$ \\
\hline$-\alpha$ & 300 & 300 & 5 \\
-1 & 450 & 600 & 10 \\
0 & 650 & 1050 & 17.5 \\
+1 & 850 & 1500 & 25 \\
$+\alpha$ & 1000 & 1800 & 30 \\
\hline
\end{tabular}

$$
\begin{aligned}
Y= & \beta_{0}+\beta 1 x_{1}+\beta_{2} x_{2}+\beta_{3} x_{3}+\beta_{11} x_{1}^{2}+\beta_{22} x_{2}^{2}+\beta_{33} x_{3}^{2}+\beta_{12} x_{1} x_{2} \\
& +\beta_{13} x_{1} x_{3}+\beta_{23} x_{2} x_{3}
\end{aligned}
$$

where $Y$ is a predicted dependent variable, $\beta_{0}$ is the offset term; $\beta_{1}$, $\beta_{2}, \beta_{3}, \beta_{11}, \beta_{22}, \beta_{33}, \beta_{12}, \beta_{13}$ and $\beta_{23}$ are the corresponding parameters estimated for each linear, quadratic and interaction terms generated by the regression equation. The adequacy of the models was determined using model analysis and coefficient of determination $\left(R^{2}\right)$.

The terms statistically found non-significant $(p>0.05)$ were dropped from the initial model and experimental data were refitted only to the significant $(p<0.05)$ parameters in order to obtain the final reduced model. It should be noted that some variables were kept in the reduced model despite non-significance $(p>0.05)$, since, a quadratic or interaction term containing this variable was significant $(p<0.05)$.

Finally, a description of significant effects obtained from ANOVA was presented by a Standardized Pareto chart.

The optimum level of independent variables can be obtained from the ridge analysis. The lipids extraction from the microalgae $N$. oculata was conducted again three times at the optimum level of independent variables for confirmation of the results. Verification of the response surface model was performed by comparing the predicted value with the experimental average value obtained from the three replications.

Once the extraction process was optimized with the three parameters fixed at their optimum values, another parameter was also tested to complete the experimental analysis. These experiments on the temperature effect were operated to detect another possible influence of this parameter on the recovered fatty acid methyl esters (FAMEs) amounts and on the quality of fatty acids (some conditions may degrade properties of the microalgae oil, for instance as a result of exposure to too high temperatures). The thermostat was then set at 5 different temperatures: $1,5,15$, 30 and $35^{\circ} \mathrm{C}$.

\subsection{Lipid analyses}

2.6.1. Preparation of fatty acid methyl esters (FAMEs), identification by gas chromatography coupled to mass spectrometry (GC-MS) and quantification by gas chromatography with flame ionization detector (GC-FID)

FAMEs were prepared from Nannochloropsis total lipids extract by using a modified fatty acids methyl ester method (Li et al., 2006) from a Morrison and Smith $(Y)$ procedure:

The sample $(\sim 1 \pm 0.01 \mathrm{mg})$ was weighed into a Pyrex tube fitted with a Teflon-lined cap and liquid was eliminated by treating the sample under a dry nitrogen flow at $35^{\circ} \mathrm{C}$. A solution $(1 \mathrm{ml})$ of sulfuric acid (5\%) in methanol was added as well as $500 \mu \mathrm{l}$ of BHT/toluene/triheptadecanoic acid mixture, prepared with $500 \mu \mathrm{l}$ of toluene, $25 \mu \mathrm{g}$ triheptadecanoic acid (as internal standard) ( $1 \mathrm{mg} / \mathrm{ml}$ in $n$-hexane) and $10 \mu \mathrm{l}$ of BHT ( $1 \%$ in methanol). The mixture was vortexed during $30 \mathrm{~s}$. The tubes were placed in an oven at $85^{\circ} \mathrm{C}$ for $90 \mathrm{~min}$. They were then removed and cooled at room temperature before adding $\mathrm{NaCl}$ ( $1.5 \mathrm{ml}, 0.9 \%$ in distilled water). $1 \mathrm{ml}$ of $n$-hexane was used for extraction and tubes were centrifuged at $4000 \mathrm{rpm}$ for $2 \mathrm{~min}$. Organic phases were collected and evaporated to dryness under nitrogen. Lipids were redissolved in $1 \mathrm{ml}$ $n$-hexane and transferred into GC vials.

FAMEs separation and identification were carried out on a FOCUS gas chromatograph equipped with a DSQ II quadrupole mass spectrometer using the electron impact ionization mode (Thermo Fisher Scientific, San Jose, USA). A polar TR-WAX column ensuring a good separation of polyunsaturated fatty acid species was used (Thermo Fisher Scientific; length $30 \mathrm{~m}$, diameter $0.25 \mathrm{~mm}$, film thickness $0.25 \mu \mathrm{m}$ ). Hydrogen was the carrier gas. 
The injector and transfer line were maintained at 225 and $250{ }^{\circ} \mathrm{C}$, respectively. The source temperature was $200^{\circ} \mathrm{C}$. Samples were injected in split mode (5:1 split ratio) at an oven temperature of $45^{\circ} \mathrm{C}$. After $1.5 \mathrm{~min}$, the oven temperature was raised to $150{ }^{\circ} \mathrm{C}$ at $15^{\circ} \mathrm{C} \mathrm{min}{ }^{-1}$ then to $240{ }^{\circ} \mathrm{C}$ at $6{ }^{\circ} \mathrm{C} \mathrm{min}-1$ and held at $240{ }^{\circ} \mathrm{C}$ for $3 \mathrm{~min}$. FAMEs were identified by retention time, fragmentation pattern and, when necessary, comparison with purified FAME standards (Larodan Fine Chemicals AB, Malmö, Sweden). FAMEs were quantified with a GC-FID (Thermo Fisher Scientific, San Jose, USA). Samples were injected in split mode (split ratio 1:5). Detector was set at $250{ }^{\circ} \mathrm{C}$. Carrier gas, column and oven temperature program were the same as for GC-MS analysis.

\subsubsection{Quantification of polar lipids by high performance thin layer chromatography}

Polar lipids such as phospholipids and glycolipids were quantified using a densitometry method by comparing to standard curves generated from known amounts $\left(0.1 \mathrm{mg} / \mathrm{ml}\right.$ concentration in $\mathrm{CHCl}_{3} /$ methanol (2:1)) of DGDG (digalactosyldiacylglycerol) - MGDG (monogalactosyldiacylglycerol) - PC (phosphatidylcholine) - PE (phosphatidylethalonamine) and PG (phosphatidylglycerol) standards (Sigma-Aldrich, Saint-Louis, USA; Larodan Fine Chemicals $A B$, Malmö, Sweden).

Typically, around $1 \mathrm{ml}$ of sample was loaded as a spot onto $20 \times 20 \mathrm{~cm}$ silica gel 60 F254 HPTLC plates (Merck KGaA, Germany) using an ATS 5 automatic TLC sampler (Camag, Switzerland).

Plates were then developed in an ADC2 automatic developing chamber (Camag) using a acetone/toluene/water (91/30/8, v/v/v) mixture as solvent for polar lipids development, thoroughly dried under the hood, dipped for $6 \mathrm{~s}$ in a modified $\mathrm{CuSO}_{4}$ reagent (Churchward et al., 2008) (20 g CuSO $4,200 \mathrm{ml}$ methanol, $8 \mathrm{ml}$ $\mathrm{H}_{2} \mathrm{SO}_{4}, 8 \mathrm{ml} \mathrm{H}_{3} \mathrm{PO}_{4}$ ), heated at $141{ }^{\circ} \mathrm{C}$ for $30 \mathrm{~min}$ on a TLC plate heater and finally scanned using a TLC Scanner 3 with WinCATs software (Camag).

\subsubsection{Scanning electronic microscopy (SEM)}

A scanning electron microscope (Philips XL3, France) was used to examine the surface of $N$. oculata cells treated with or without ultrasonic assisted extraction. Operating voltage was $10 \mathrm{kV}$ and the vacuum was set. Samples deposited on a hydrophilic mixed cellulose esters filter of $13 \mathrm{~mm}$ diameter $(0.45 \mu \mathrm{m}$ porosity) were coated with a thin layer of gold with a "sputter coater".

\section{Results and discussion}

\subsection{Fitting the model}

Response surface methodology (RSM) was used to study the influence of the ultrasonic power, of the extraction time and of the percentage of dry weight on the response $Y$. Coded and uncoded experiments and responses obtained for each run (by GC-FID-MS analysis of total FAMEs amounts) of the central composite design are listed in Table 2. The following regression equation for oil recovery $(Y)$ was acquired:

$$
\begin{aligned}
Y= & -0.078+0.00033 x_{1}+0020 x_{2}-0.0041 x_{3}+0.0000039 x_{1}^{2} \\
& +0.000022 x_{1} x_{2}-0.000073 x_{1} x_{3}+0.000019 x_{2}^{2}-0.0010 x_{2} x_{3} \\
& +0.00054 x_{3}^{2}
\end{aligned}
$$

Table 3 presents the statistical significance of each coefficient through $p$-values by an analysis of variance (ANOVA). These data showed that the differences in two linear terms $\left(x_{2}, x_{3}\right)$, one quadratic term $\left(x_{3}^{2}\right)$, and one interaction term $\left(x_{2} x_{3}\right)$ were significant $(p<0.05)$, while the other terms $\left(x_{1}, x_{1}^{2}, x_{2}^{2}, x_{1} x_{2}\right.$ and $\left.x_{1} x_{3}\right)$ were not significant $(p>0.05)$. Those significant terms have a remark- able impact on the response, playing a dominant role in general oil extraction by ultrasounds, whereas the non-significant terms had a negligible influence. As a result, a refined equation was obtained by neglecting most of the non-significant terms and the final predictive equation obtained is as given below:

$$
\begin{aligned}
Y= & -0.128+0.0012 x_{1}+0022 x_{2}-0.0039 x_{3} \\
& -0.000073 x_{1} x_{3}-0.0010 x_{2} x_{3}+0.00053 x_{3}^{2}
\end{aligned}
$$

Results observed by the $p$-value significance can also be pointed out on a Pareto chart of standardized effects, presented on Fig. 1 where effects have been standardized and are proposed with a relative importance order. The lengths of bars are proportional to the absolute magnitude of the estimated effects of coefficients while the vertical line represents the minimum magnitude of statistically significant effects for the response studied, with a 95\% confidence interval. Only one linear effect (\% dry weight (DW)) appeared to be highly significant, followed by the interaction effect of the extraction time and the percentage of dry weight $\left(x_{2} x_{3}\right)$. In addition, interaction effect of power and \% DW $\left(x_{1} x_{3}\right)$ did not cross the dashed line and is quite far to be significant at the $95 \%$ level.

In other words, these results clearly mean that the percentage of dry weight, which represents the viscosity of the medium, is the most significant factor impacting the recovered FAMEs amounts via ultrasounds. The more viscous the medium is, the lower the recovered FAMEs amounts will be. The extraction duration is also a significant factor, the recovered FAMEs amounts increasing with the extraction time. However in association with the percentage of dry weight, the interaction factor represents a more important influence and overall a negative one on the yield. That means that an increase in the extraction with the viscosity of the medium decreases the recovered FAMEs amounts.

Power has no direct influence in this design model. The ultrasonic power will truly play a role on the extraction yield if the viscosity of the medium is acceptable.

ANOVA also demonstrated that the model adequately represents the real relationship between the parameters, giving a high coefficient of determination $\left(R^{2}=90.05 \%\right)$.

\subsection{Optimized model of extraction}

To determine optimal levels of the variables for oil extraction from the $N$. oculata fresh cells, three-dimensional response surface plots (Fig. 2) were constructed according to the Eq. (1). This graphical representation allows visualization of the major relationship linking levels of variables and responses. Each plot of the graphs underlines the response function of two variables with the third variable fixed to its central point.

As observed before, it clearly appears that the effect of ultrasonic power is not directly significant on the oil recovery. However, these surfaces illustrate the major influence of percentage of dry weight, e.g., the medium density. The yield (recovered FAMEs amounts) of each experiment is mainly controlled by this parameter. If this value is too high, other parameters (extraction time for example) have no direct influence. It is shown that oil yield increases with duration except if the medium is too concentrated in microalgae cells, then the yield will not be optimal. This is a negative interaction between these two parameters.

Acoustic cavitation phenomenon is evocated to explain these results. When a liquid is irradiated by ultrasounds, micro-bubbles are formed, they grow and oscillate extremely fast, and eventually collapse powerfully if the acoustic pressure is high enough (Mason, 1990). These collapses, when occurring near a solid surface, induce micro-jets and shock waves that hit the matrix, generating fragmentation and disruption of the cellular surface for example. Because of extreme conditions inside the bubbles (about $5000 \mathrm{~K}$, 
Table 2

Box-Behnken design of process variables along with observed values for the $Y$ response.

\begin{tabular}{|c|c|c|c|c|c|c|c|}
\hline \multirow[t]{2}{*}{ Treatment runs } & \multicolumn{3}{|c|}{ Coded variables } & \multicolumn{3}{|c|}{ Process variables } & \multirow[t]{2}{*}{ Recovered FAMEs amounts $\mu \mathrm{g} / \mathrm{g}$ DW } \\
\hline & $x_{1}{ }^{\mathrm{a}}$ & $x_{2}{ }^{\mathrm{b}}$ & $x_{3}{ }^{\mathrm{c}}$ & Power (W) & Extraction time $(\mathrm{s})$ & $\%$ DW & \\
\hline 1 & -1 & +1 & -1 & 450 & 1500 & 10 & 2236.0 \\
\hline 2 & 0 & 0 & 0 & 650 & 1050 & 17.5 & 436.0 \\
\hline 3 & $+\alpha$ & 0 & 0 & 1000 & 1050 & 17.5 & 586.8 \\
\hline 4 & +1 & +1 & +1 & 850 & 1500 & 25 & 251.9 \\
\hline 5 & +1 & -1 & -1 & 850 & 600 & 10 & 138.7 \\
\hline 6 & 0 & 0 & $+\alpha$ & 650 & 1050 & 30 & 171.0 \\
\hline 7 & 0 & 0 & 0 & 650 & 1050 & 17.5 & 136.5 \\
\hline 8 & +1 & -1 & +1 & 850 & 600 & 25 & 131.0 \\
\hline 9 & 0 & 0 & $-\alpha$ & 650 & 1050 & 5 & 2493.1 \\
\hline 10 & -1 & +1 & +1 & 450 & 1500 & 25 & 333.5 \\
\hline 11 & -1 & -1 & -1 & 450 & 600 & 10 & 89.0 \\
\hline 12 & $-\alpha$ & 0 & 0 & 300 & 1050 & 17.5 & 534.5 \\
\hline 13 & 0 & $+\alpha$ & 0 & 650 & 1800 & 17.5 & 512.3 \\
\hline 14 & 0 & 0 & 0 & 650 & 1050 & 17.5 & 442.0 \\
\hline 15 & -1 & -1 & +1 & 450 & 600 & 25 & 341.0 \\
\hline 16 & 0 & 0 & 0 & 650 & 1050 & 17.5 & 408.4 \\
\hline 17 & 0 & 0 & 0 & 650 & 1050 & 17.5 & 542.4 \\
\hline 18 & 0 & 0 & 0 & 650 & 1050 & 17.5 & 997.4 \\
\hline 19 & +1 & +1 & -1 & 850 & 1500 & 10 & 2606.0 \\
\hline 20 & 0 & $-\alpha$ & 0 & 650 & 300 & 17.5 & 475.9 \\
\hline
\end{tabular}

a Ultrasound power (W)

b Extraction time (s).

c Percentage of dry weight (\% DW).

Table 3

ANOVA for experimental results.

\begin{tabular}{llllll}
\hline Source & Sum of squares & Df $^{* *}$ & Mean Square & $F$-ratio & $p$-Value \\
\hline Linear & & & & & \\
$x_{1}$ & 0.00000645145 & 1 & 0.00000645145 & 0.01 & 0.9419 \\
$x_{2}$ & 0.0156494 & 1 & 0.0156494 & 13.54 & $\mathbf{0 . 0 0 4 3}$ \\
$x_{3}$ & 0.0476064 & 1 & 0.0476064 & 41.18 & $\mathbf{0 . 0 0 0 1}$ \\
Quadratic & & & & & \\
$x_{1}^{2}$ & 0.0000363531 & 1 & 0.0000363531 & 0.03 & 0.8628 \\
$x_{2}{ }^{2}$ & 0.0000173514 & 1 & 0.0000173514 & 0.02 & 0.9049 \\
$x_{2}^{2}$ & 0.0134659 & 1 & 0.0134659 & 11.65 & $\mathbf{0 . 0 0 6 6}$ \\
Interaction & & & & & \\
$x_{1} x_{3}$ & 0.000974832 & 1 & 0.000974832 & 0.84 & 0.3801 \\
$x_{1} x_{2}$ & 0.000094078 & 1 & 0.000094078 & 0.08 & 0.7813 \\
$x_{2} x_{3}$ & 0.0267381 & 1 & 0.0267381 & 23.13 & $\mathbf{0 . 0 0 0 7}$ \\
Total error & 0.0115602 & 10 & 0.00115602 & & \\
Total (corr.) & 0.116174 & 19 & & & \\
\hline
\end{tabular}

** Degree of freedom.

$2000 \mathrm{~atm})$, also called hot spots, the jets are very powerful and play a role of assistance in extraction. Thus, extraction rate increases, energy consumption is reduced and solvent use can be switched in order to obtain a "green" process.

Nevertheless, ultrasonic cavitation is a physical phenomenon whose performance depends on some parameters, especially viscosity. When the natural cohesive forces acting within a liquid (e.g., high viscosity and high surface tension) are high, cavitation is difficult to attain (Mason, 1992). This physical approach explains, for a fixed ultrasonic power, the lower recovered FAMEs amounts when the percentage of dry weight is high.

In summary, the optimum conditions identified from this model involved an ultrasonic power at its maximum, $1000 \mathrm{~W}$, a $1800 \mathrm{~s}$ extraction time and a $5 \%$ of dry weight which represents a solution rather than a paste.

Under these conditions, oil recovery obtained from $N$. oculata fresh matter has been predicted to be at $0.48 \%$ (by a dosage of the total fatty acid methyl esters by GC-FID-MS). If this result is compared to a Bligh and Dyer (1959) reference yield, realized on $10 \mathrm{mg}$ of fresh microalgae, the difference is quite important. By

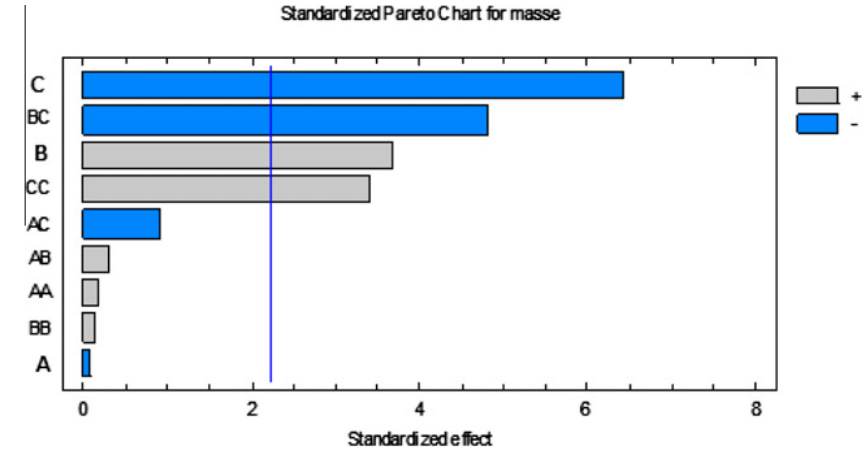

Fig. 1. Standardized Pareto chart. $A=$ power, $B=$ extraction time, $C=$ percentage of dry weight (DW).

analyzing the total fatty acid methyl esters from a Bligh and Dyer extraction, the oil yield has been evaluated at 5.7\% (this microalgae, as underlined before, is not starved). Thus, on small amounts of fresh matter, the conventional extraction using a solvent mix is about twelve times more efficient than a solvent-free extraction on ten thousand times higher amounts.

Then these conclusions were checked by re-running these experiments in triplicate under the new conditions, which are now optimal ultrasound-assisted extraction conditions, and compared the predicted results with experimental data. A mean recovery value of $0.2 \pm 0.03 \%$ was obtained from the actual experiments, which not reached the value of $0.48 \%$ predicted by the model equation. This bad correlation between experimental and predicted values especially indicates that the quadratic model is not really predictive, although it properly represents the experimental points of the design. The optimum predicted value is placed outside the experimental points; this high value is not well representative because the model's validity is worse at the borders, as it frequently occurs with a quadratic model.

At the borders, the limit of feasibility is reached, for instance it will be difficult to decrease again the percentage of dry weight of the medium below $5 \%$, because the lipid contents will reach the 

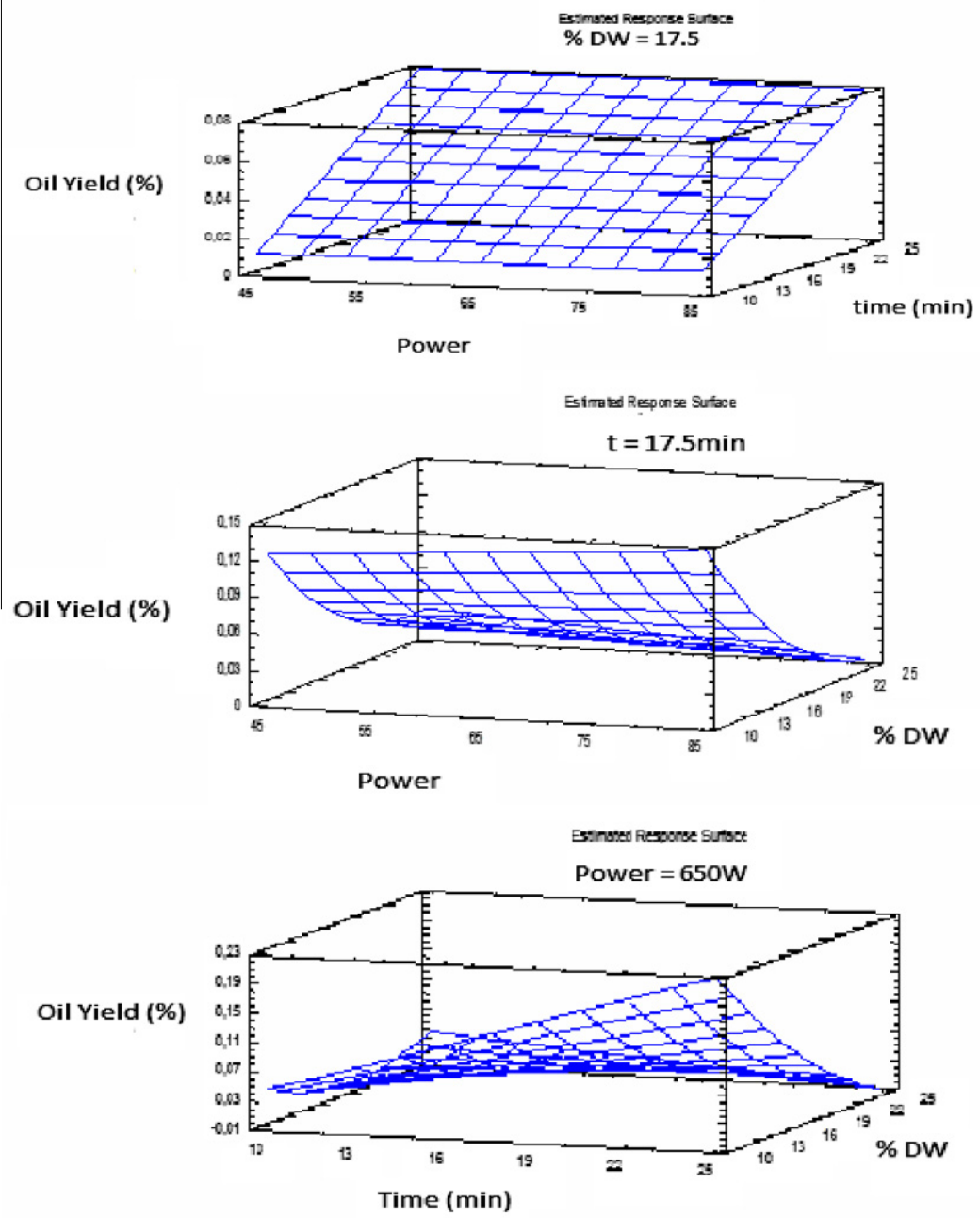

Fig. 2. Response surface plots showing effects of power, extraction time and percentage of dry weight on oil recovery from Nannochloropsis oculata fresh cells.

recoverable and detection limits. It is also possible to increase the extraction duration beyond $30 \mathrm{~min}$, but the threshold of the recovered FAMEs amounts is probably not really far from this time. This hypothesis may be validated by the fact that temperature in the medium no longer increases, as it is demonstrated hereafter.

The conclusion on this optimum is that an algal solution will give better yields than a paste, and the explanation is purely physical, as shown before. Thus, an ultracentrifugation step in a more general procedure could be avoided. It also must be noted that the oil recovery is complex as its content is low in $100 \mathrm{~g}$ of fresh matter in a non-starved microalgae; in addition, oil is often caught up in an emulsion that it is not easy to break at this level. At a larger scale, yields might be higher due to a probable better demulsifying operation generated on more concentrated phases. In this work, yields are accurate to tenth.

\subsection{Effect of temperature on the recovered FAMEs amounts}

In order to improve performance of ultrasound-assisted extraction, it has been decided to modulate the temperature in the double glass reactor according to the optimal conditions found above in the experimental design. Five temperatures have been tested in ascending order: $1,5,15,30$ and $35^{\circ} \mathrm{C}$. In all these experiences, it has been noted that oil recovery increased from $0.15 \%$ to $0.24 \%$ when the thermostat temperature increases from 1 to $35^{\circ} \mathrm{C}$ that is the oil recovery increases about one and a half times. Thus, this optimized extraction model for $N$. oculata fresh matter would be a $1000 \mathrm{~W}$ ultrasonic assisted extraction, a 30 min extraction time, a $5 \%$ DW cellular solution of microalgae and an external temperature surrounding the experimental system at $35^{\circ} \mathrm{C}$.

\subsection{Fatty acid composition}

3.4.1. Analysis of the total fatty acid methyl esters (FAMEs) by gas chromatography coupled with flame ionization detector and mass spectrometry

The measurement of oil recovery was based on the total amount of FAMEs in each sample. So it is a real yield in total fatty acids, and it is certainly a much more accurate value than a yield obtained by a gravimetric method. Table 2 resumes the results of the twenty experiments. It is obvious that, according to operating conditions, the recovered fatty acid methyl esters amounts substantially vary. The best oil recovery is given by the experiments number one, nine and nineteen. Through these three experiments, percentage of dry weight is low and the extraction time is longer than $15 \mathrm{~min}$. The spreads between their oil recoveries are low and yet the ultrasound power parameter is defined with an important variance. This result on the minor effect of power in the design has already been developed in the statistical analysis before.

Fig. 3 shows the classes' variability of FAMEs in connection with the treatment applied. There is a majority of polyunsaturated fatty acids (PUFAs), then of (monounsaturated fatty acids) MUFAs and 
finally a minority of saturated fatty acids (SFAs). In general, unsaturated fatty acids represent more than $80 \%$ of total fatty acids. The statistical model giving the optimum, analyses were repeated three times following these new operating conditions. The total recovered FAMEs amounts as well as the chemical profiles of FAMEs were compared to those obtained after the conventional extraction method by Bligh and Dyer. Oil recoveries are very different, and by a Bligh and Dyer process, FAMEs yield is $5.7 \%$ against $0.2 \%$ on a triplicate average by the UAE optimized method. Table 4 indicates that the two methods extract in the same proportion the different lipid compounds, but with different efficiencies. Although these differences are small, it can be noted that palmitoleic acid C16:1n7 is better extracted by UAE than eicosapentaenoic acid (EPA C20:5n3).

Finally, when the thermal effect on the yield value was studied, the lipid compounds in each experiment were also analyzed. The distribution of FAMEs depends on the sample treatment. It is remarkable that profiles are different depending on temperatures. Generally, when the temperature rises, the amounts of MUFAs and SFAs, and particularly those of $\mathrm{C} 16$ and $\mathrm{C} 16: 1 \mathrm{n} 7$, tend to decrease; these compounds seem to be deteriorated by heat. The reverse trend is observed with the EPA whose content increases with temperature. So it is possible to obtain FAMEs' classes contents adjusted according to the extraction process used.

\subsubsection{Analysis of polar lipids by high performance thin layer chromatography}

For further lipid analysis, high-performance thin-layer chromatography (HPTLC) with densitometry has been performed to characterize and quantify the various polar lipid classes in the microalgae after a Bligh and Dyer extraction and an ultrasonic assisted extraction in optimum conditions. Five standards in a mixture of phospholipids and glycolipids (DGDG (Digalactosyl diacylglycerol) - MGDG (Monogalactosyl diacylglycerol) - PC (phosphatidylcholine) - PE (phosphatidylethalonamine) and PG (phosphatidylglycerol)) were deposited on the plate at different concentrations. Pigment standards (astaxanthin, zeaxanthin, canthaxanthin and chlorophyll a were also deposited in order to check if the polar lipids are well separated from pigments. For this reason, the quality of the quantification by densitometry was better.

As shown in Fig. 4, there is a majority of phospholipids compared glycolipids in the two samples $(80 \%$ for UAE $+\mathrm{N}$ OPT $+\mathrm{T}$ method and $78 \%$ for Bligh and Dyer extraction). However any homogeneity of distribution between the two extraction methods was found. For instance, extraction assisted with ultrasounds is better for PC and DGDG, while the conventional method with solvent gives a better resolution for PE, PG and MGDG. From a global quantification point of view, the oil recovery is at $5.47 \%$ for the
Table 4

Fatty acid methyl esters composition of Nannochloropsis oculata obtained by UAE.

\begin{tabular}{lll}
\hline \multirow{2}{*}{ FAMEs } & \multicolumn{2}{l}{ FAMEs composition (wt.\%) } \\
\cline { 2 - 3 } & $\mathrm{BD}+\mathrm{N}$ & $\mathrm{UAE}+\mathrm{N}$ OPT \\
\hline $\mathrm{C} 14: 0$ & 7.4 & 7.4 \\
$\mathrm{C} 16: 0$ & 16.8 & 14.5 \\
$\mathrm{C} 18: 0$ & 0.4 & 1.5 \\
$\mathrm{C} 16: 1(n-7)$ & 27.1 & 33.6 \\
$\mathrm{C} 16: 1(n-9)$ & 1.6 & 0 \\
$\mathrm{C} 18: 1(n-9)$ & 4.5 & 4.0 \\
$\mathrm{C} 18: 1(n-7)$ & 0.4 & 0.5 \\
$\mathrm{C} 16: 2(n-6)$ & 1.2 & 1.7 \\
$\mathrm{C} 18: 2(n-6)(\mathrm{LA})$ & 2.6 & 1.5 \\
$\mathrm{C} 18: 3(n-6)(\mathrm{GLA})$ & 0.7 & 0.0 \\
$\mathrm{C} 20: 4(n-6)(\mathrm{AA})$ & 3.4 & 5.3 \\
$\mathrm{C} 16: 3(n-3)(\mathrm{HTA})$ & 0.0 & 0.5 \\
$\mathrm{C} 20: 5(n-3)(\mathrm{EPA})$ & 33.8 & 29.6 \\
$\sum n-3$ & 6.7 & 7.2 \\
$\sum n-6$ & 7.9 & 8.5 \\
\hline
\end{tabular}

$\mathrm{BD}+\mathrm{N}$ : Bligh and Dyer extraction with a non-starved microalgae.

$\mathrm{UAE}+\mathrm{N}$ OPT: ultrasound-assisted Extraction (UAE) with non-starved microalgae and in optimal conditions.

conventional method by a Bligh and Dyer procedure and $0.12 \%$ for UAE in optimal conditions with a cryostat temperature adjusted at $35^{\circ} \mathrm{C}$. These values are very close to those obtained by the global quantification of FAMEs by GC-FID-MS analysis. Nevertheless, a biais exists and it underestimates the amount of polar lipids in the microalgae cells. Two hypotheses may explain this problem. Only five standards were available at the moment of these experiments and other polar lipids, for example PI (phosphatidylinositol) and SG (sterol glycoside) could have been quantified (Wang and Wang, 2011). The second hypothesis involves the presence of free fatty acids.

Finally, absence of triacylglycerols (TAGs) in significant amount has been observed. This is a logical result, since the microalgae which were harvested were not cultivated in starvation conditions. Cells did not accumulate representative TAGs.

\subsubsection{Fresh microalgae microstructure}

In order to understand the mechanism of ultrasound-assisted extraction (UAE) from $N$. oculata fresh cells, their microstructures have been studied using scanning electron microscopy (SEM). Morphology of non-extracted as well as UAE cells were studied. With UAE, external structure of cells surface has changed. Cells are smaller and the parietal system has been damaged, particularly some spaces show the wall cell disruption through which cellular contents were probably released. This demonstrates the effect of the

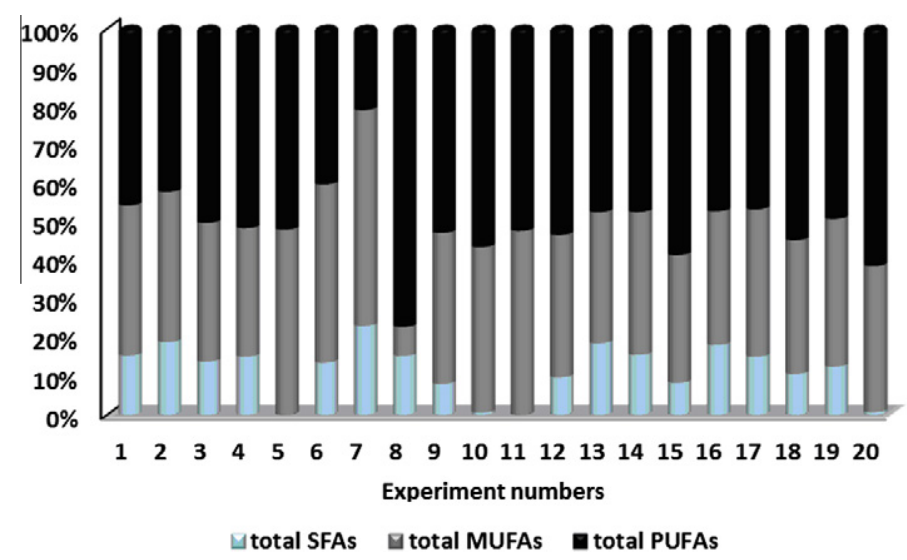

Fig. 3. Distribution analysis of FAMEs classes by GC-FID-MS, on the ultrasound-assisted extraction experimental design. 


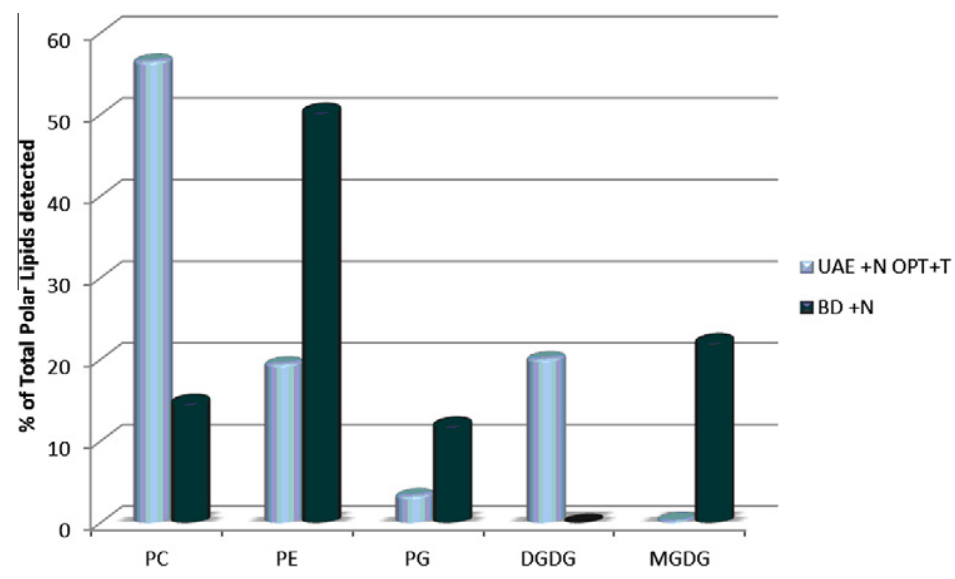

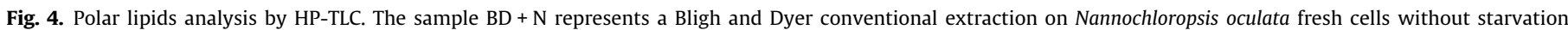

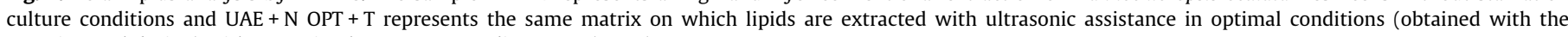
experimental design) with an optimal temperature adjustment $\left(35^{\circ} \mathrm{C}\right)$.

physical phenomenon of cavitation on the cells structure. In contrast, the surfaces of fresh samples, not treated by an extraction process, appear to be relatively intact and quite smooth. Some folds on the parietal wall have been observed likely due to the filter drying operation on the sample.

Finally these results clearly highlight the efficiency of mass transfer by ultrasounds treatment. With water as a solvent, oil, in a acceptable volume, is separated in two distinct phases, which simplifies the oil recovery.

\subsection{Cost, sustainable and scaling-up approaches}

The reduced cost of extraction is clearly advantageous for the proposed ultrasound-assisted extraction method in terms of time, energy and volume of solvent. Conventional process mainly needs several unit operations such as: microalgae's drying, solid-liquid extraction using petroleum solvent, filtration and finally solvent evaporation to collect the final crude oil. With this preliminary study of an innovative process assisted by ultrasounds, it needs two unit operations: ultrasonic treatment of the microalgae solution followed by a centrifugation step which allows separation of water-oil-defatted microalgae.

The result showed that the potential use of ultrasounds was promising for extraction at an industrial scale. Ultrasound-assisted extraction could also be performed to treat larger quantities of microalgae by using existing large scale ultrasound extraction reactors already used in food or chemical fields such as batch ultrasound systems with volume size ranging from 100 to $1000 \mathrm{~L}$ (www.etsreus.com) or in continuous mode with volume treated ranging from 100 to $5000 \mathrm{~L} / \mathrm{h}$ (www.hielsher.com). These ultrasound reactors are suitable for the extraction of 10,20 or $200 \mathrm{~kg}$ equivalent dry microalgae per hour. Theses reactors could be easily modified and used for ultrasound-assisted extractions.

\section{Conclusion}

Ultrasound-assisted extraction of fresh microalgae was revealed in its optimum operating conditions. With non-starved microalgae, it has been proven that oil recovery is possible in a reduced time and with a simple and scalable pre-industrial device. If total FAMEs amounts are lower than those obtained with a conventional solvent extraction, the quality of fatty acids is preserved.

This extraction method should be performed in further researches with higher amounts of fresh biomass cultivated in starvation conditions for a biodiesel production prospect and in a continuous flow mode system which probably represents a more convenient and suitable industrial-scale process.

\section{Acknowledgements}

This study has been achieved in the context of the "Salinalgue Project" (FUI-France) conducted by La Compagnie du Vent. We thank Isabelle Bornard (INRA, Avignon) for scanning electron micrographs and Patrick Carrier and Stéphan Cuiné (HélioBiotec platform) for technical assistance in lipid analysis.

\section{References}

Andrich, G., Nesti, U., Venturi, F., Zinnai, A., Fiorentini, R., 2005. Supercritical fluid extraction of bioactive lipids from the microalga Nannochloropsis sp. Eur. J. Lipid Sci. Technol. 107, 381-386.

Balasubramanian, S., Allen, J.D., Kanitkar, A., Boldor, D., 2011. Oil extraction from Scenedesmus obliquus using a continuous microwave system - design, optimization, and quality characterization. Bioresour. Technol. 102, 3396-3403.

Bligh, E.G., Dyer, W.J., 1959. A rapid method for total lipid extraction and purification. Can. J. Biochem. Physiol. 37, 911-917.

Brown, T.M., Duan, P., Savage, P.E., 2010. Hydrothermal liquefaction and gasification of Nannochloropsis sp. Energy Fuels 24, 3639-3646.

Chemat, F., Zill-.E, H., Khan, M.K., in press. Applications of ultrasound in food technology: processing, preservation and extraction. Ultrason. Sonochem.

Churchward, M.A., Brandman, D.M., Rogasevskaia, T., Coorssen, J.R., 2008. Copper (II) sulfate charring for high sensitivity on-plate fluorescent detection of lipids and sterols: quantitative analyses of the composition of functional secretory vesicles. J. Chem. Biol. 1 (1-4), 79-87.

Cravotto, G., Boffa, L., Mantegna, S., Perego, P., Avogadro, M., Cintas, P., 2008 Improved extraction of vegetable oils under high-intensity ultrasound and/or microwaves. Ultrason. Sonochem. 15, 898-902.

Du, Z., Li, Y., Wang, X., Wan, Y., Chen, Q., Wang, C., Lin, X., Liu, Y., Chen, P., Ruan, R., 2011. Microwave-assisted pyrolysis of microalgae for biofuel production. Bioresour. Technol. 102 (7), 4890-4896.

Gerhard, K., 2008. "Designer" biodiesel: optimizing fatty ester composition to improve fuel properties. Energy Fuels 22, 1358-1364.

Gottel, M., Eing, C., Gusbeth, C., Frey, W., Muller, G., 2011. Influence of Pulsed Electric Field (pef) Treatment on the Extraction of Lipids from the Microalgae Auxenochlorella protothecoides. Plasma Science (ICOPS), Abstracts IEEE International Conference, Chicago.

Halim, R., Gladman, B., Danquah, M.K., Webley, P.A., 2011. Oil extraction from microalgae for biodiesel production. Bioresour. Technol. 102 (1), 178-185.

Hanhua, H., Kunshan, G., 2003. Optimization of growth and fatty acid composition of a unicellular marine picoplankton, Nannochloropsis sp., with enriched carbon sources. Biotechnol. Lett. 25, 421-425.

Krienitz, L., Wirth, M., 2006. The high content of polyunsaturated fatty acids in Nannochloropsis limnetica (Eustigmatophyceae) and its implication for food web interactions, freshwater aquaculture and biotechnology. Limnol. Ecol. Manag. Inland Waters 36 (3), 204-210.

Lee, J.Y., Yoo, C., Jun, S.Y., Ahn, C.Y., Oh, H.M., 2010. Comparison of several methods for effective lipid extraction from microalgae. Bioresour. Technol. 101, s75-s77.

Li, Y.H., Beisson, F., Pollard, M., Ohlrogge, J., 2006. Oil content of Arabidopsis seeds: the influence of seed anatomy, light and plant-to-plant variation. Phytochemistry 67 (9), 904-915. 
Mason, T.J., 1990. Chemistry with Ultrasound. Elsevier Applied Science, New-York. Mason, T.J., 1992. Practical Sonochemistry: User's Guide to Applications in Chemistry and Chemical Engineering. Ellis Horwood Ltd., New York.

Mata, T.M., Martins, A., Caetano, N.S., 2010. Microalgae for biodiesel production and other applications: a review. Renew. Sustain. Energy Rev. 14 (1), 217-232.

Mercer, P., Armenta, R.E., 2011. Developments in oil extraction from microalgae. Eur. J. Lipid Sci. Technol. 113, 539-547.

Patil, P.D., Gude, V.G., Mannarswamy, A., Deng, S., Cooke, P., Munson-McGee, S Rhodes, I., Lammers, P., Nirmalakhandan, N., 2010. Optimization of direct conversion of wet algae to biodiesel under super critical methanol conditions. Bioresour. Technol. http://dx.doi.org/10.1016/j.biortech.2010.06.31.

Ranjan, A., Patil, C., Moholkar, V., 2010. Mechanistic assessment of microalgal lipid extraction. Ind. Eng. Chem. Res. 49 (6), 2979-2985.

Richmond, A., 2004. Handbook of Microalgal Culture: Biotechnology and Applied Phycology. Blackwell, Oxford.
Sander, K., Murthy, G., 2009. Enzymatic Degradation of Microalgal Cell Walls. ASABE Paper No.: 096054. ASABE Annual International Meeting.

Scott, S.A., Davey, M.P., Dennis, J.S., Horst, I., Howe, C.J., Lea-Smith, D.J., Smith, A.G., 2010. Biodiesel from algae: challenges and prospects. Biotechnology 21, 277286.

Singh, J., Gu, S., 2010. Commercialization potential of microalgae for biofuels production. Renew. Sustain. Energy Rev. 14, 2596-2610.

Wang, G., Wang, T., 2011. Characterization of lipid components in two microalgae for biofuel application. J. Am. Oil Chem. Soc. http://dx.doi.org/10.1007/s11746011-1879-8.

Wiyarno, B., Yunus, R.M., Mel, M., in press. Extraction of algae oil from Nannochloropsis sp.: a study of soxhlet and ultrasonic-assisted extractions, J. Appl. Sci. ISSN 1812-5662 (O), 1812-5654 (P). 